\title{
$\beta$ Style Free-Piston Stirling Engine Control System Research
}

\author{
Jian $\mathrm{Xu}^{1, \mathrm{a}}$, Yongsheng Zhang ${ }^{2}$ \\ ${ }^{1}$ Institute of Mechanical Manufacturing Technology, China Academy of Engineering Physics, 621900 Mianyang \\ China \\ ${ }^{2}$ Department of Mechanical Engineering Sichuan Engineering Technical Colleg , 618000 Deyang China
}

\begin{abstract}
For the Free-Piston Stirling Engines (FPSE) control system, a three -phase bridge circuit is reused as the system output about rectifier and start inverter. When FPSE system is in the power stage, the double closed loop control strategy and optimization algorithm of PI control parameters is adopted to ensure the highest system transmission efficiency under the requirements of the system output power and guarantee the stability of the running system. The simulation results prove the effectiveness of the above research content.
\end{abstract}

\section{Introduction}

For traditional internal combustion rotary generators, their weaknesses contain low efficiencies, too much noise, big volumes and high emissions. And their loss increases due to the complexity of mechanical transmission structures, which reduces the generating efficiency[1-2]. However, the use of Free-Piston Stirling Engines reduces intermediate mechanical transmission structures, which makes the system more compacted, reliable and small-sized. Meanwhile, the system efficiency rises dramatically. Aiming at Free-Piston Stirling Engines control problems, due to the lag of power electronic technology in early stages, series capacitances are generally used to give reactive power compensation for output voltage of linear generators. Document [3] proposes that the control of stirling engines can be divided into several levels including energy management, control of air-fuel ratio and control of Stirling Engines motion track. Aiming at shortcomings of the direct current voltage non-adjustment of uncontrolled diode rectifier and great current harmonics, Document[4] proposes three-phase bridge PWM rectifier circuit, merely giving the stability control method of DC bus voltage, without doing any power compensation and power factor correction work. Sunpower company proposes two methods of output power control for Stirling Engines system. One controls the system temperature ratio to control output power and the other controls the stroke of the engines[5].Royal Institute of Technology researches the impact on whole stirling generator of forces of different prime motor waves[6-7]. Through verification, the efficiency reaches maximum and power fluctuation reaches minimum if the current waveform is the same as that of velocity.

Based on current FPSE control system researches, the three-phase bridge circuit is reused as the system output rectification and starting inverter multiplex circuit[8-10]. When FPSE is on the generation condition and requirement of reaching system output power, double closed loop control and PI control strategies which can ensure the highest system transmission efficiency are given. It

\footnotetext{
${ }^{a}$ Corresponding author : tq08psx@qq.com 
increases the stability and reliability of the system and promotes the development of FPSE technology as well.

\section{FPSE System Structure and Principle}

The FPSE control system proposed in this paper has functions including motor starting, electric power transformation with active power factor correction, generation power control of motor, system temperature and working medium pressure control. The control system structure of Stirling motor is shown in Figure 1. The functions above are separately realized by main controllers and secondary controllers. This paper focuses on control progress under the FPSE generation condition, which is controlled by main controllers.

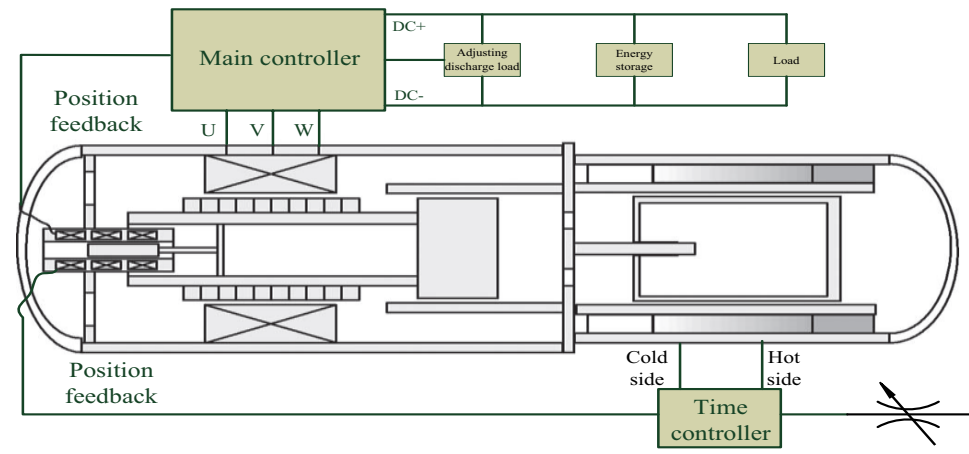

Figure 1. Schematic diagram of control structure

Main controllers are relative to motor starting module, three-phase rectification circuit, power control module, electricity storage module, communication module and so on. Energy storage device controlled by main controllers provides electrical energy for motor staring and starting circuit provides starting current for motor stator coil thus creates magnetic field, providing transient excitation for permanent magnetism and driving the startup of motor. The three-phase rectification module uses rectifier with $\mathrm{PFC}$ to convert larger ranging $\mathrm{AC}$ to nearly constant $\mathrm{DC}$ output voltage ( high voltage), and maintain the best power factor, improve efficiency of electricity source. On the premise that the structure parameters, temperature ratio and working medium average pressure of Stirling motor is constant, the stroke of power piston is also relative to system's total power load, which consists of user load and discharge load. The change of total power load will result in the magnetic force change of motor wires, thus affects the stroke of power piston. Therefore, the stability control of power piston is not a direct control. Meanwhile, the system has energy storage part, which can stabilize load pressure at transient time of load variation. Besides satisfying the power consumption of user loads, the system can store surplus power into power storage module, which increases the reserve of emergency power.

\section{FPSE System Power Generation State Control and Parameter Optimization}

The working states of main controllers can be divided into two stages: starting and power generation stage. The starting stage is not the key attention of this paper. At the power generation stage of Stirling Engine, the AC output of generator needs rectification and filtering in order to be transformed into DC, needed by power consumption equipment. However, due to the introduce of nonlinear part and large filter capacitor, the motor current becomes steep leading and trailing pulsating current, which results in larger current distortion, input and output phase difference, thus causes lower system efficiency and larger system loss. In order to solve this problem and increase Stirling Engine system's 
power factor, in this paper, the controlled rectifier with power factor correction is used to control the system, which makes the waveform of the system motor current and output voltage consistent and zero-phase difference, improving the system efficiency. In order to satisfy the power demand of different equipment, the voltage part is introduced to adjust output the voltage value in real time, satisfying demand of different users.

The Stirling Engine system power stage control is shown as Figure 2. The "voltage outer ring, current inner ring" double closed loop control strategy is used. The "voltage outer ring" is used to adjust the output value of the system load in real time, which makes it fast and without static error tracking set value. The "current inner ring" is to correct the system power factor. When user loads vary, a discharge load is used to match its variation, making total power load at a constant value and ensuring the power piston stroke nearly unchanged.

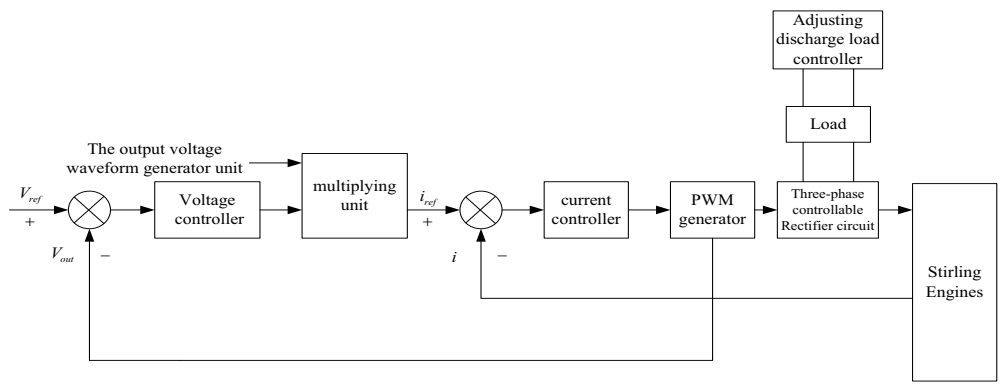

Figure 2. System power stage control chart

Under FPSE system generation condition, the system power density and transmission power are closely related to PI control parameters. The system PI control parameter optimization is an important way to improve the system comprehensive performance. FPSE system is a non-linear, multi-parameter, multi-goal, uncertain and tight coupling system. So, based on non-linear optimization theories, artificial intelligence like neural network and genetic algorithm are mixed to realize the PI control parameter optimization.

Combined with penalty function to deal with restricted problems, dynamic functions are used to improve individual fitness calibration and non-uniform mutation. High-pressure power electronic device with less conduction losses, lower output distortion and lower total load voltage variation are proposed as goals in system's PI control parameter design methods.

a) Optimize objective variables, use penalty functions to deal with restricted problems and decide a suitable weight coefficient to form objective function, which is about to optimize. Less switching loss, lower voltage of high frequency power electronic device and voltage stability of load output are the goal. Assume $a_{f}, a_{s}, a_{c}$ each stands for conduction loss coefficient of $\mathrm{f}$, output current distortion of $I_{s}$ and total load output voltage variation $U_{c}$. System optimizing objective function $f_{o b j}$ is formed:

$$
f_{o b j}=a_{f} f+a_{s} I_{s}+a_{c} U_{c}+\sum_{i=1}^{n} b_{i} \max \left(g_{i}, 0\right),\left(g_{i}<0\right)
$$

where, $\mathrm{n}$ stands for numbers of system restricted conditions, $g_{i}$ is the actual restricted condition. Since a lower $f_{o b j}$ is better, when $g_{i}$ satisfies restricted conditions, on the contrary, $\max \left(g_{i}, 0\right)=0 ;, \max \left(g_{i}, 0\right)=g_{i}$. The increase of $f_{o b j}$ punishes individuals which violates restrictions.

b) BP neural network mathematical expression mixed with genetic algorithm is shown as follows:

$$
\left\{\begin{array}{l}
\min \mathrm{E}(w, v, \theta, r)=\frac{1}{2} \sum_{k=1}^{M} \sum_{t=1}^{n}\left[y_{k}(t)-\hat{y}_{k}(t)\right]^{2} \\
s, t: w \in R^{\mathrm{m} \times \mathrm{p}}, \quad v \in R^{n \times p}, \theta \in R^{p}, r \in R^{n}
\end{array}\right.
$$


where, $E_{l}$ is the total error of the network, $w$ and $\theta$ are weight and threshold value of BP neural network, $y_{k}(t)$ is the expectancy output, $\hat{y}_{k}(t)$ is the network actual output.

$$
\hat{y}_{k}(t)=f_{o b j}\left\{\sum_{j=1}^{P} v_{\mu} \cdot f_{o b j}\left[\sum_{i=1}^{m} w_{i j} \cdot x_{i}(t)+\theta_{j}\right]\right\}+r_{i}
$$

Assume $E_{2}=\frac{1}{N-N_{1}} \sum_{k=N_{1}}^{M} \sum_{t=1}^{n}\left[y_{k}(t)-\hat{y}_{k}(t)\right]^{2}$ is the mean square error of test sample, showing the reliability estimate of network output. Lower $E_{2}$ means higher network reliability, otherwise it is not that reliable.

c) Combined with conditions a and $b$, the genetic algorithm is used to do chromosome encoding, selection ,chiasma, disorder and fitness selection repeatedly, thus obtains the optimized variables.

Finally, the satisfied condition of restriction is examined. If not completely satisfied or without solution, weight coefficient, genetic operation parameters or restricted ranges can be adjusted properly. Through multiple optimizations, the optimized variable which fully satisfied restrictions can be obtained.

\section{Simulation Result Analysis}

\subsection{Simulation analysis without control strategy}

In order to verify the effectiveness of control strategy analysis and controller design in power stage, Stirling system without control is simulated first, which foreshadows the verifying effectiveness of control strategy, shown as Figure 3. The system model parameters are shown in Table.1.

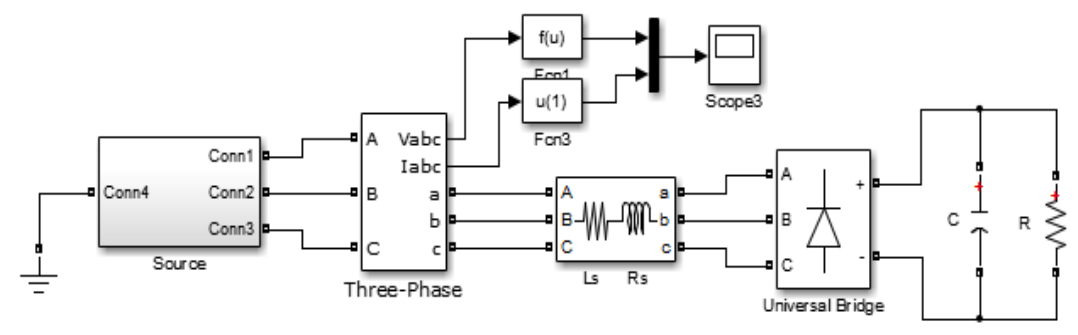

Figure 3. Simulink model without control strategy in power stage

Table 1. model parameters in power stage

\begin{tabular}{|c|c|c|}
\hline name & signs & value \\
\hline Power frequency & $\mathrm{F}$ & $80 \mathrm{~Hz}$ \\
\hline Supply voltage effective value & $\mathrm{U}$ & $380 \mathrm{~V}$ \\
\hline Internal resistance & $\mathrm{Rs}$ & $0.02 \Omega$ \\
\hline Inductance & $\mathrm{Ls}$ & $10 \mathrm{mH}$ \\
\hline Filter capacitor & $\mathrm{C}$ & $2.5 \mathrm{mF}$ \\
\hline Load resistance & $\mathrm{R}$ & $600 \Omega$ \\
\hline
\end{tabular}

Simulation waveform in Fig.5 can be obtained by simulation, which is a steady stage waveform. Figure $4 \mathrm{a}$ ) is the contrast chart of motor current and back EMF. For better observing the contrast condition, simulation back EMF is 10 times lower and it is observed with oscilloscope. As figures shows, back EMF and motor current differ in waveform and phase. Back EMF is a standard 
sinewave while the motor current is a pulsate current with a high distortion, which has a large harmonic wave and hardly can be used in engineering application. Figure 4b) shows the output voltage in load ends, with a stable DC output voltage at $473 \mathrm{~V}$ and output power at $3.7 \mathrm{~kW}$.

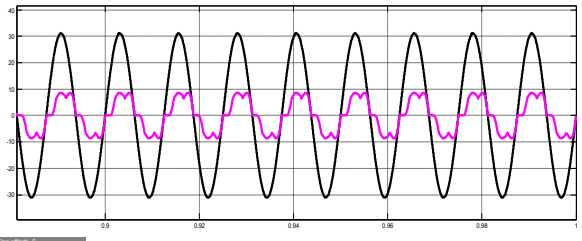

a) contrast of motor current and back EMF

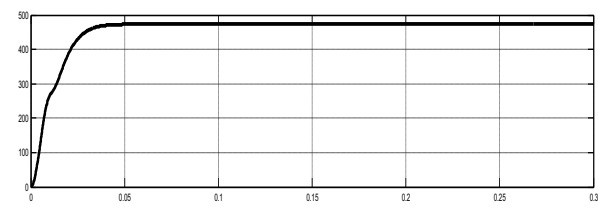

b) output voltage waveform at load ends

Figure 4. Simulation waveform without control strategy in power stage

\subsection{Simulation analysis using double closed loop control strategy}

Through the analysis of control strategy in the power stage and PI control parameter optimization, the simulink model in Stirling engine power stage can be established as Figure 5a). Voltage outer ring and current inner ring is used and switch drive signal of controlled rectifier circuit can be produced by PWM algorithm. Control module is a self-defined package module, with the internal simulation module in Figure 5b). The output voltage value at load ends is compared with set value and produces control variable through PI. This control variable is multiplied by motor current set value and used as motor current given value. The given value is compared with the actual motor current value and three control variables are obtained by $\mathrm{P}$ controller. The control model in Figure 5. produces three corresponding control variables according to voltage, current and feeding value. Control variables are amplitude-limited and six switch drive signals are produced by PWM module to control threephase circuit, where PWM module is a self-defined module. Control variables and STW carrier are compared and square wave with controllable duty ratio can be obtained. Therefore, the switch conduction condition can be controlled. Optimized parameters of double closed loop control network can be obtained according to formula (3), shown as Table. 2 .

Table 2. Parameters control in power stage

\begin{tabular}{|c|c|c|}
\hline name & signes & value \\
\hline Output voltage given & Uref & $600 \mathrm{~V}$ \\
\hline Voltage ring proportion coefficient & $\mathrm{Pu}$ & 1 \\
\hline Voltage ring integral coefficient & $\mathrm{Iu}$ & 30 \\
\hline Current ring proportion coefficient & $\mathrm{Pi}$ & 25 \\
\hline
\end{tabular}

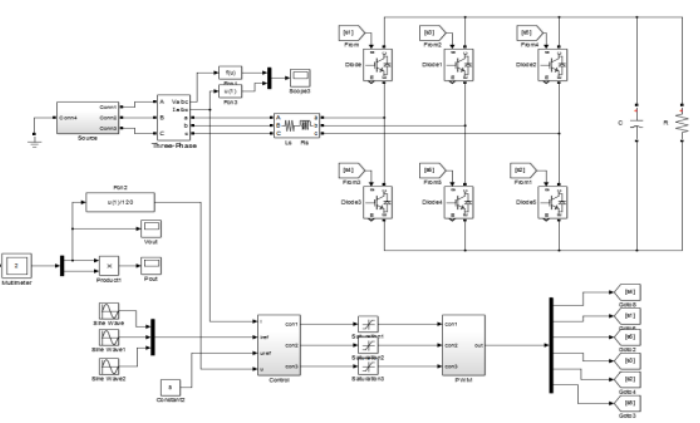

a) Stirling generation simulation system with double closed loop models

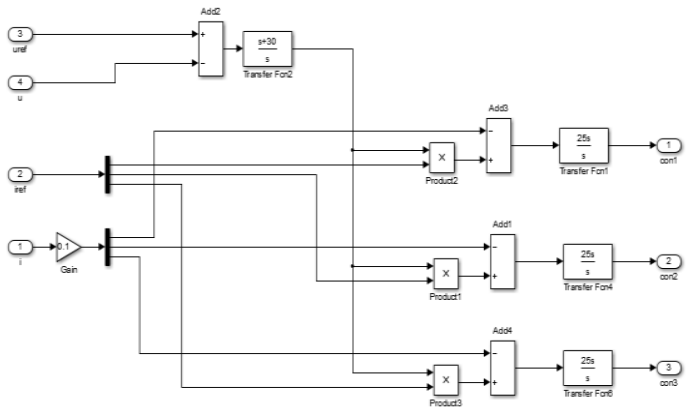

Figure 5. Simulink simulation model in power stage 
The steady-state simulation waveform in Figure 6. can be obtained by simulation. Figure 6 a) is the contrast figure of motor current and back EMF. The amplitude of back EMF is also lowered by 10 times. By double closed loop control, the motor current is not the previous pulsate form but consistent with back EMF waveform, whose phase difference is zero and the system power factor and efficiency is improved. Figure $6 \mathrm{~b}$ ) shows the output voltage of load ends. It can be seen the output DC voltage can be stabilized at set value of $600 \mathrm{~V}$, output power at $6 \mathrm{~kW}$. Under "current inner ring control ", back EMF and motor current can be the same in waveform and phase difference, thus improves the power factor. Under "voltage outer ring control", the output voltage can be effectively adjusted and it can track the set value fast ,static-error free, which satisfies the need of different electrical equipment. Through the above control strategies, the control demand of Stiring engine in power stage is almost realized.

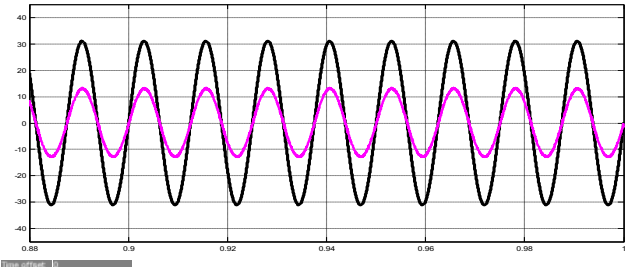

a) Waveform contrast of motor current and back EMF

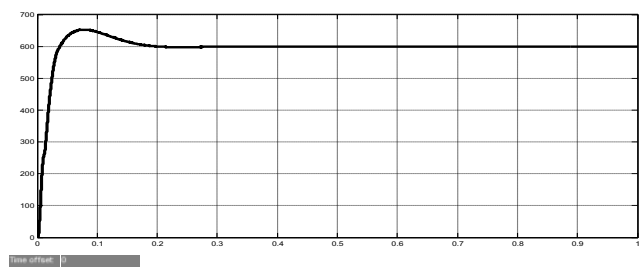

b) Voltage waveform of load ends

Figure 6. Double closed loop control strategy simulation waveform in power stage

\section{Conclusion}

A three-phase bridge circuit is reused as the system output about rectifier and start inverter. Reaching the system output power demand, double closed loop control strategy which ensures the highest transmission efficiency and its control parameter optimization is given. Aiming at time-varying load resulting in the change of system output voltage, a method which realizes offset control using resistance matrix is proposed, thus maintains the total power load at a constant value. As a result, the piston stroke will hardly change. The simulation result verifies the effectiveness of researches above.

\section{References}

1. Li Qingfeng, Xiao Jin, Huang zhen Simulation of a Free Piston Linear Alternator[J] China Mechanical Engineering 2009,20(8):911-915

2. Shoukry E F Numerical Simulation for Parametric Study of a Two-stroke Compression Ignition Direct Injection Linear Engine[D].Morgantown: West Virginia University, 2003

3. Scott S.Gerber, Mike J, Timothy F.Regan, Mary E R. Advanced Controller for the Free-Piston Stirling Convertor[C].13 ${ }^{\text {th }}$ International Stirling Engineering Conference. 2005:1-12

4. Yimin Lu,Huang X F,Zhu Z Q. Direct Power Control of a Permanent Magnet Linear Generator in a Free Piston Energy Converter[C].International Conference on Electrical Machines and Systems.2008:3636-3639

5. Holliday E, Keiter D E. Control Electronics for Palm Power $35 \mathrm{~W}$ Free-Piston Stirling Engine[C].3 ${ }^{\text {rd }}$ International Energy Conversion Engineering Conference.2005:1-7

6. Hannson J,Leksell M,Carlsson F. Minimizing Power Pulsations in a Free Piston Energy Converter[C].European Conference on Power Electronics and Applications.2005

7. Liu Y, Leksell M, Arshad W M, Thelin P. Influence of Speed and Current Profiles upon Converter Dimensioning and Electrical Machine Performance in a Free-Piston Generator[C]. Proceedings of the $4^{\text {th }}$ International Symposium on Linear Drives for Industry Application.2003

8. Van Blarigan,P.Free-piston engine[P].United States Patent ,US 6,199,519 B1,Alexandria,VA,2001

9. Scott Goldsborough,Peter Van Blarigan .Optimizing the Scanvenging System for a Two-Stroke Cycle, Free Piston Engine for High Efficiency and Low Emissions:A Computational Approach [C]. International Multidimensional Engine Modeling User Group Meeting at the SAE Congress 2003

10. Jiabin Wang,David Howe.Design Optimization of Radially Magnetized ,Iron-Cored,Tubular Permanent Magnet Machines and Drive Systems[J].IEEE Transactions on Magnetics Vol.40,NO.5,Sep 2004 